\title{
IMPLEMENTATION OF COVID-19 VACCINE TEMPERATURE MONITORING AND TRACKING SYSTEM
}

\author{
Aboobacker Sidheeq Varamb Muriyan \\ Laboratory Technologist \\ Department of Electromechanical Engineering \\ Institute of Applied Technology \\ Abu Dhabi Polytechnic, United Arab Emirates
}

\author{
Mahra Ali Alblooshi \\ UG Student in Electrical Engineering \\ Department of Electromechanical Engineering \\ Institute of Applied Technology \\ Abu Dhabi Polytechnic, United Arab Emirates
}

\author{
Shumookh Ahmed Alshehhi \\ UG Student in Electrical Engineering \\ Department of Electromechanical Engineering \\ Institute of Applied Technology \\ Abu Dhabi Polytechnic, United Arab Emirates \\ Abdulla Nabil Saeed \\ UG Student in Mechatronics Engineering \\ Department of Electromechanical Engineering \\ Institute of Applied Technology \\ Abu Dhabi Polytechnic, United Arab Emirates
}

\author{
Mohammed Ebrahim Alshehhi \\ UG Student in Mechatronics Engineering \\ Department of Electromechanical Engineering \\ Institute of Applied Technology \\ Abu Dhabi Polytechnic, United Arab Emirates
}

\begin{abstract}
This paper is concerned with the design and implementation of real-time temperature control, monitoring, and tracking system for COVID-19 Vaccines. COVID-19 Vaccines must be stored properly from the manufacture's time until the administration's time to people. The proper vaccine maintenance during the transportation stage known as the cold chain process. An excellent temperature-controlled supply chain involves all equipment and procedures used in the transportation, storage, and handling of COVID-19 vaccines. By maintaining temperatures recommended by the vaccine manufacture, implementing best storage and handling practices, providers can ensure that patients will get the full benefit of the COVID-19 vaccines they receive. In this project, the Arduino-based controller automatically monitors and preserves the vaccine box's temperature as per the prescribed WHO (World Health Organization) standard and alarming the system if deflection in the standard range happens. The tracking system in this project implement by using another Arduino-based GPSGSM module for the vaccine suppliers or hospitals to track the exact location of the designed Vaccine box. In addition, a portable case solar battery charge design to ensure an uninterrupted power supply during transportation.
\end{abstract}

Keywords - Handling, Storage, Suppliers, Tracking, Transportation, Temperature, Vaccines, World Health Organization

\section{INTRODUCTION}

Vaccines are an effective way to protect against some dangerous diseases, which should be saved under certain conditions and are suitable for the people who treat them unless the heat spoils them while delivering process. It is one of the most difficult challenges, as it is forced in some remote parts of the world to transfer these valuable and essential treatments through the small cool refrigerators. The $\mathrm{s}$ vaccine's success depends on how well the vaccine is stored correctly, which requires unique criteria for it, such as the temperature required and the method of transporting it. The quality of the vaccine affects the effectiveness and safety of the treatment and depends on proper manufacturing and preservation: high-quality vaccines are available when obtained according to analytical procedures from reliable suppliers when transported and stored in conditions that conform to the exemplary requirements conservation. The cold chain system is used for storing vaccines in good condition and sometimes called the immunization supply chain or the vaccine supply chain. It includes a series of links designed to keep vaccines within WHO-recommended 


\section{International Journal of Engineering Applied Sciences and Technology, 2021 \\ Vol. 6, Issue 2, ISSN No. 2455-2143, Pages 5-12 \\ Published Online June 2021 in IJEAST (http://www.ijeast.com)}

temperature ranges, from the point of manufacture to the end of the administration. Figure 1 illustrates the complete cold chain. The bottom row of arrows shows the flow of vaccines down to the health facilities; the top row of hands shows where data are collected, recorded, checked, analyzed, and how reporting information flows back up the chain. Following this sequence ensures that cold chain performance is properly monitored and that the necessary information is gathered for vaccine forecasting.

A cold chain must include during the transportation of the vaccines. It starts from the vaccine factories, kept at a specific temperature, then shipped with good packaging under a temperature-monitored box for shipping, then to warehouses and kept there; then, it is distributed to centers to maintain a specific temperature. The vaccine's cold chain function is to save product quality from the manufacture's time until the administration's point by ensuring that vaccines are stored and transported within WHO-recommended temperature ranges.

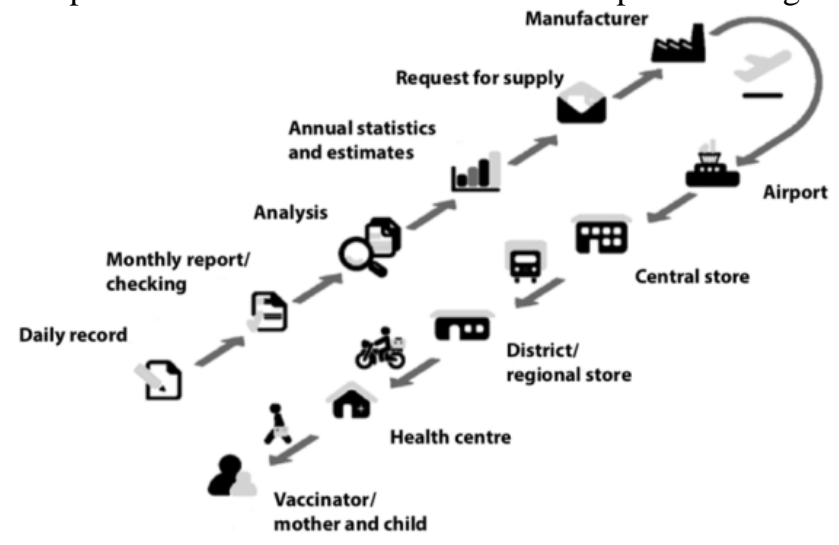

Fig. 1. Cold chain process

There are following observed vital procedures that maintain a reliable vaccine cold chain at the peripheral level. First, vaccines and diluents should store well within the required temperature range at all sites; second, vaccines are pack and transport from outreach sites according to recommended procedures and keep vaccines and diluents within recommended cold chain conditions during immunization sessions. Some vaccines are sensible to biological products and are volatile to freezing, light, and others to heat. Vaccine efficacy, meaning it can protect the vaccinated patient adequately, can diminish when exposed to inappropriate temperatures. The vaccine will not regain back potency once lost. Covered vaccines can maintain quality from temperature extremes, and then the cold chain will meet specific temperature requirements.

The main objective of this paper is to find a solution for COVID-19 vaccines that must be saved, stored, and transported excellently under specific temperatures below very high zero Celsius. However, this project aims to design an efficient COVID-19 vaccine box that monitors the vaccine's temperature to save vaccines from heat and freezing, which should be kept at the correct temperature when manufactured until used with an administered excellent cold chain system. In addition, track and send the object's location on the mobile phone using GPS-GSM modules while the transportation stage. The cold chain consists of a series of storage and transport links designed to keep vaccines within an acceptable range until it reaches the user. It will also use a portable case solar battery charge to safeguard from the interrupted power supply during transportation.

\section{LITERATURE REVIEW}

Traditional vaccines are usually stored between 35 degrees Fahrenheit and 46 degrees Fahrenheit, but some of the leading COVID-19 vaccines need to be stored at much colder temperatures. Moderna's vaccine requires a storage temperature of minus 4 degrees Fahrenheit, whereas Pfizer's vaccine candidate requires a storage temperature of minus 94 degrees Fahrenheit. These are not easy temperatures to maintain accurately so COVID-19 vaccines are various from the rest of the regular vaccines which enforced to be maintained with a high temperature below zero that need to be stored at much colder temperatures from the moment it is packed to the moment it is injected into people when it transferred through several logistical centers - storage areas, before being delivered to hospitals and other facilities. This will require preparing planes, warehouses, and trucks with freezers, and the vaccine must be placed in glass bottles that can withstand the freezing climate. A number of the leading Covid-19 vaccines under development will need to be kept at temperatures as low as minus 80 degrees Celsius (minus 112 degrees Fahrenheit) from the moment they are bottled to the time they are ready to be injected into patients' arms. That will not be easy. Vaccines may be manufactured on one continent and shipped to another. They will go from the logistic hub before ending up at the hospitals and other facilities that will administer them. However, when vaccines are transported from health centers to remote populations, temperatures inside vaccine carriers are often maintained with ice packs, putting the vaccines at risk of freezing. Many vaccines containing aluminum adjuvants are freeze sensitive and costly.

\section{A. Cold Boxes}

Cold boxes, vaccine carriers and ice packs are used for keeping vaccines cold during transportation. In comparison with cold boxes, vaccine carriers have a smaller volume, suitable for use by health workers during immunization campaigns and out-reach services. As these are passive devices, coolant packs are accessories for both cold boxes and vaccine carriers providing the cooling energy/warming for a limited period. 


\section{International Journal of Engineering Applied Sciences and Technology, 2021 \\ Vol. 6, Issue 2, ISSN No. 2455-2143, Pages 5-12 \\ Published Online June 2021 in IJEAST (http://www.ijeast.com)}
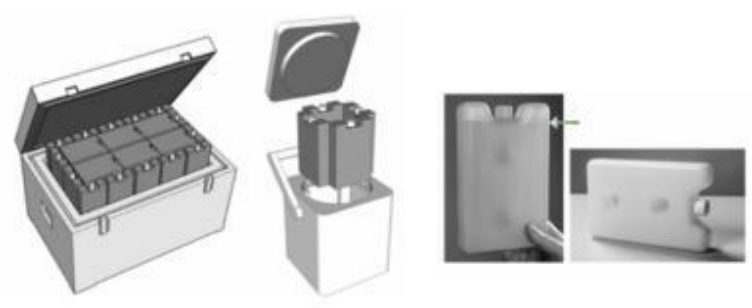

Fig.2. Watermark Extraction algorithm Block Diagram

A cold box is an insulated container that can be lined with ice packs to keep vaccines and diluents cold during transportation and/or short period storage (from two to seven days). Cold boxes are used to collect and transport monthly vaccine supplies from district stores to the health facility. They are also used to store vaccines when the refrigerator is out of order or being defrosted and for outreach and mobile sessions in addition to vaccine carriers.

\section{B. Vaccine carriers}

Like cold boxes, vaccine carriers are insulated containers that, when lined with frozen ice-packs, keep vaccines and diluents cold during transportation and/or temporary storage. They are smaller than cold boxes and are easier to carry if walking. But they do not stay cold as long as a cold box maximum for 48 hours with the lid closed. Vaccine carriers are used to transport vaccines and diluents to outreach sites and for temporary storage during health facility immunization sessions. In small health facilities they are used to bring monthly vaccine supplies from the district store. Vaccine carriers are also used to store vaccines when the refrigerator is out of order or is being defrosted.

\section{Ice - packs}

Ice packs are bottles that has a flat, square plastics shape used to filled water and frozen. Ice-packs are used to keep vaccines cool inside the vaccine carrier or cold box. The required numbers of ice-packs for a cold box or vaccine carrier are varies. Ice-packs need to condition before using them in a vaccine carrier.

\section{Foam pads}

A foam pad is a piece of soft foam that fits on top of the icepacks in a vaccine carrier. There are some incisions on it to allow vaccines to be inserted in the foam. During immunization sessions, the foam pad serves as a temporary lid to keep unopened vaccines inside the carrier cool while providing a surface to hold, protect and keep cool opened vaccine vials. Previously, ice packs were used to keep vaccines cool during immunization sessions outside of vaccine carriers. It is now recommended to use the supplied foam pads for this purpose.

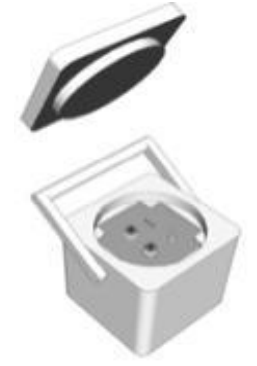

Fig .3. Foam pad in use

Suitable rigid containers will always use to reduce damage to vaccines during transit and maintain temperature. Domestic cool bags should not use to store, distribute, or transport vaccines. Cool packs from a recognized medical supply company and the validated cool boxes (with maximumminimum thermometers should be used [13]. The individual manufacturer's instructions should robustly adhere to the Summary of Product Characteristics with Electronic Medicines Compendium (EMC). Vaccines are protected in the original packaging (or similar insulation material) and stored in a cool box with cool packs wrapped in bubble wrap or as the manufacturers' instructions recommend [13]. The vaccine and cool packs will not contact immediately. Then the vaccine is protected from damage, such as being frozen.

\section{IMPLEMENTATION METHODOLOGY}

The Vaccine Temperature Monitor and Tracking box covers all the COVID-19 vaccines requirements, which led to have an efficient cold chain system. The device's purpose is to monitor the temperature. Firstly, in the block diagram below shown in fig. 4, the device will start working once the switch turned "ON." The power is produced by a $12 \mathrm{~V}$ DC solar panel, which will operate all the electric components and supply the necessary power.

The Arduino requires a 5V DC power supplied through the DC-TO-DC converter, which will step down the voltage to the required level. The temperature cooling system will start operation when the temperature exceeds the set temperature, and the sensor will sense the changes. Then the signal will notify the indicator. A buzzing sound will arise to inform the medical staff that changes in the temperature beyond the required range will trigger the cooling system's operations. However, to preserve the necessary temperature, the LCD will be showing the temperature during these stages of the process. 


\section{International Journal of Engineering Applied Sciences and Technology, 2021 \\ Vol. 6, Issue 2, ISSN No. 2455-2143, Pages 5-12 \\ Published Online June 2021 in IJEAST (http://www.ijeast.com)}

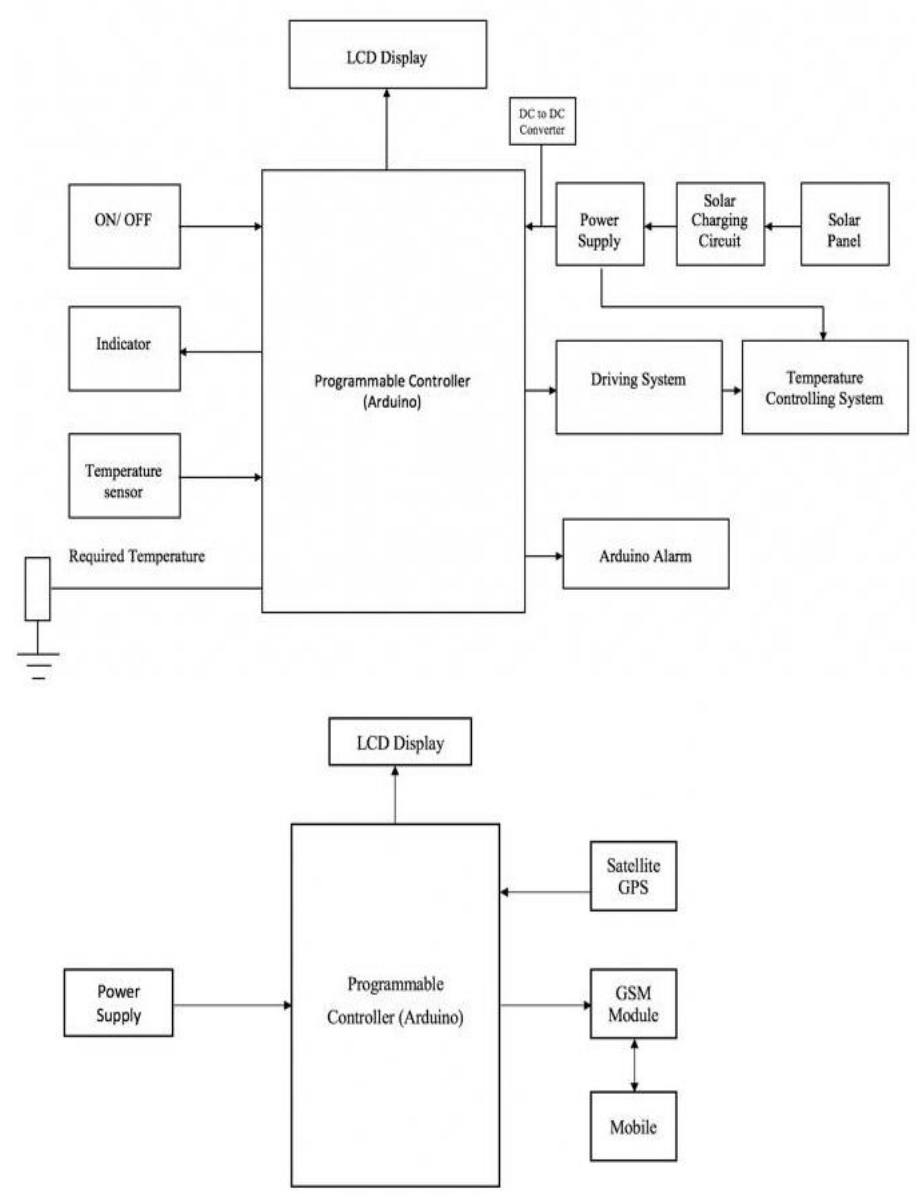

Fig. 4. Block Diagram of Monitor and Tracker Systems

The second feature is the tracking system shown in the below second block diagram in Fig. 4 connected to the GPS and GSM system. Firstly, the $12 \mathrm{~V}$ DC solar cell panel will operate the LCD; the GSM system will supply the necessary power. The GPS will send signals to the Arduino receiver, and then the Arduino will start working according to this signal until it recognizes the exact location of the shipment. After that, the GSM will start sending a text message to the assigned mobile number with the coordinates. Fig.4. below shows two block diagrams of monitor and tracker systems.

The monitoring vaccine box with proper storage and monitoring equipment will set up correctly, and a flow chart shows process stages. In Fig.5. below, the program will get started simultaneously once the switch turned on at the monitor flow chart. The indicator will indicate and read the temperature using the temperature sensor and directly display it on the LCD screen. When the temperature goes out of the range, the alarm will turn on. In contrast, the temperature regularly monitors by the repeated indicated process.

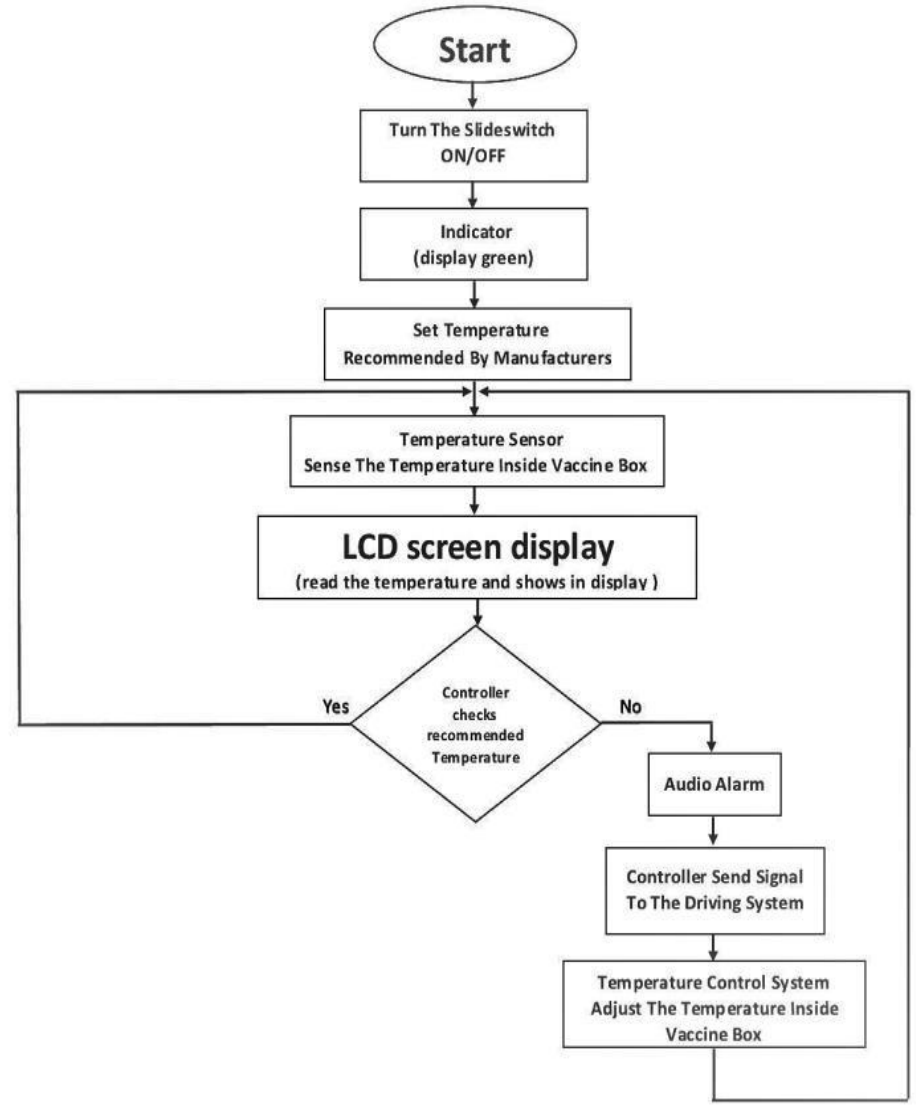

Fig .5. Monitor Flow Chart

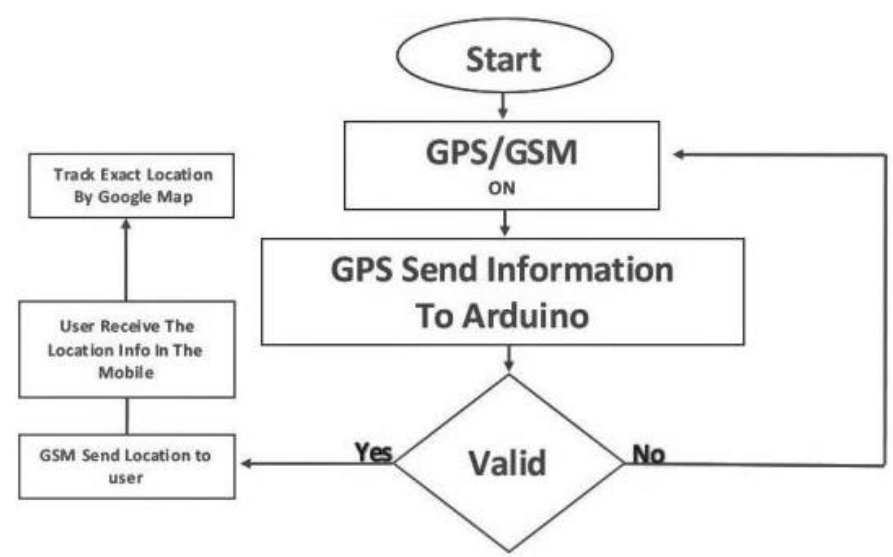

Fig.6. Tracker Flowchart

This implementation involves GPS to locate and track our vaccine box in telling us exactly its location. It is using Arduino to control the operation of GPS. Therefore, the tracker Flow chart in Fig.6. above shows the procedure starting when the GPS/GSM will it turned on. GPS is a receiving device used to discover location coordinates that are sent by SMS by using GSM. After turning on, the GPS will send the information to the Arduino. If it is valid, the GSM will send the assigned mobile number with the coordinates 


\section{International Journal of Engineering Applied Sciences and Technology, 2021 \\ Vol. 6, Issue 2, ISSN No. 2455-2143, Pages 5-12 \\ Published Online June 2021 in IJEAST (http://www.ijeast.com)}

\section{SOFTWARE CODE AND SIMULATION}

The below figures show simulation result and the code of the temperature monitoring system's circuit connection. This system work when the switch is on and achieved three conditions when the temperature is $>-20{ }^{\circ} \mathrm{C}$, the cooler, buzzer, and the red light will be $\mathrm{ON}$, and when the temperature is less than -70 Celsius over cold the cooler will be OFF. Both of the buzzer and light will be ON, but when the temperature is between $-70{ }^{\circ} \mathrm{C}$ and $-20{ }^{\circ} \mathrm{C}$, all cooler, buzzer, and light will be OFF since it is in good condition. The system will immediately stop when the switch turned off.

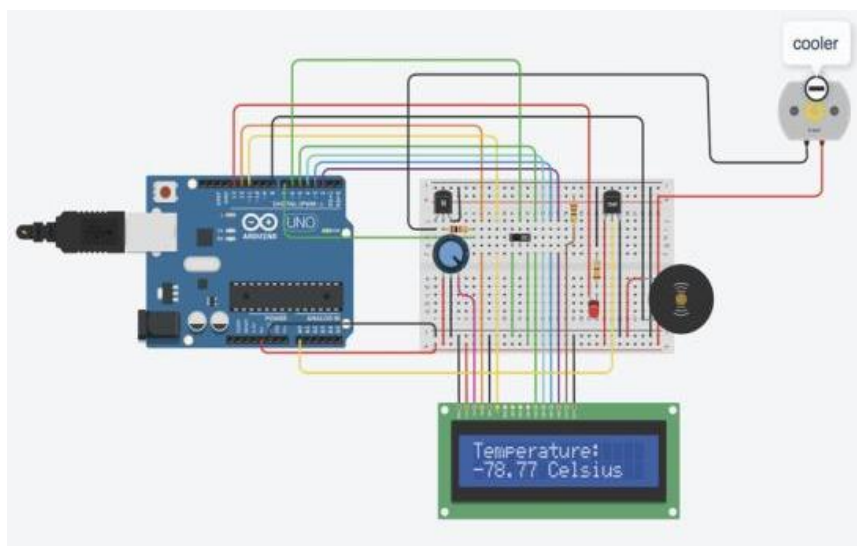

Fig.7. Simulation Results

For the Simulation, We used the Tinkercad software to simulate the Arduino of the temperature monitoring system connected the Arduino to the breadboard, and took $5 \mathrm{~V}$ and GND to both polarities breadboard to facilitate the other components connection. The LCD connection having some spatial pins to connect to the Arduino to GND and used the resistor to protect the LCD from burning by the current. Also, the students used the potentiometer to control the brightness of the LCD. The potentiometer has three terminals, terminal 1, terminal 2, and wiper; terminal 1 connected with $5 \mathrm{~V}$ of Arduino, the wiper connected to GND. Terminal 2 connected to contrast the LCD pin at the end of brightness, adjusted by the potentiometer. The declaration of the LCD is Liquid Crystal LCD (RS, enable, d4, d5, d6, d7) and connected to the Arduino pins.

The temperature sensor is the device that will make the whole project's main action depend upon the temperature reading. The temperature sensor has three terminals, which were the power, volt, and GND. The power terminal connected to $5 \mathrm{~V}$ of Arduino, the volt connected to the analog pin to took the reading from the temperature sensor, and the last terminal, which is the GND that connected to the GND of the Arduino. The declaration temperature sensor first must use analogRead to read the sensor's value. The value divided by 1024 because of the analog pins, which was $2^{\wedge} 10=1024$, multiplied the number 5 to have it in the form of voltage. The next thing offset was subtracted, which was 0.9 , and then multiplied by 100 to have it in Celsius degree.

A buzzer or piezo, in our case, will warn us by giving a warning sound. It has only two legs or two terminals, positive and negative - the positive portion connected to GND and the negative connected to the digital pins. The declaration of the buzzer tone (Arduino pin, frequency in $\mathrm{Hz}$, duration in milliseconds). The frequency must not be lower than $31 \mathrm{HZ}$ because it may damage the buzzer; the buzzer will make a sound if the temperature exceeds -20 and if it's below -70 ; otherwise will be in normal mode.

The LED that the students used to warn more addition of buzzer. Still, the students programmed the LED as an emergency case is to keep the LED blinking. The declaration of blinking led happened using digital writing, either high or low, with a delay. It is essential to have a 220 -ohm resistor to protect the led from burning; the LED will blink if the temperature exceeds -20 Celsius and if it's below -70 Celsius; otherwise will be in normal mode.

The last component, a DC motor used instead of a cooler, and the cooler's purpose was to cool down the vaccine. The cooler (DC motor) works with $5 \mathrm{~V}$ and is connected to a PNP transistor to protect the Arduino from the high current. In other words, it was switching the high currents loads; the transistor has three terminals, which are base, emitter, and collector. The collector connected to terminal 1 of (DC motor), the base associated with a resistor and then to digital pins, and the last thing the positive terminal of the external battery connected to the terminal 2 of (DC motor) and the negative terminal is must connected to the GND of the Arduino.

The slide switch is the key of the whole circuit, which that allowing the flowing of current. It has three terminals (terminal 1, common and terminal 2). Terminal 1 connected to the GND, and to read the state of a slide switch, the common connected to the digital pin. Then the third terminal connected to the source pin. Declaration of slide switch must declare an analog Read and assign it to another variable and used if condition to differentiate either high or low.

\section{HARADWARE CONFIGURATION \& RESULTS}

Fig.8., Fig.9., and Fig.10. shows Tracking System Implementation Circuit, Tracking System - Hardware Connection and Tracking System- SMS Message respectively. 
International Journal of Engineering Applied Sciences and Technology, 2021

Vol. 6, Issue 2, ISSN No. 2455-2143, Pages 5-12

Published Online June 2021 in IJEAST (http://www.ijeast.com)

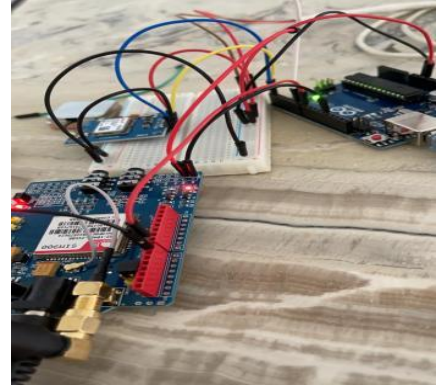

Fig.8. Tracking System - Implementation Circuit
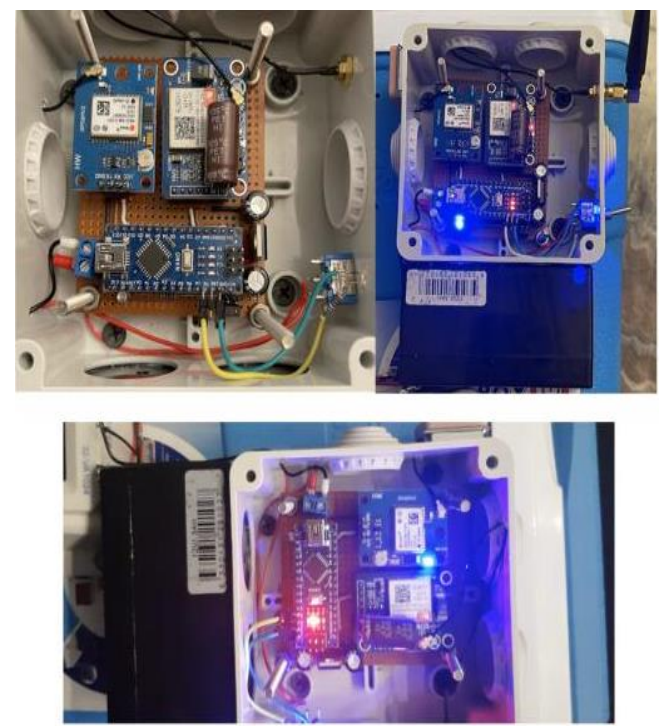

Fig.9. Tracking System - Hardware Connection

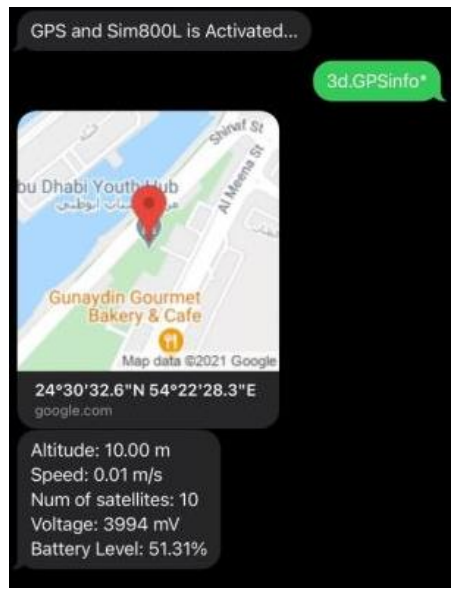

Fig.10. Tracking System- SMS Message

Fig.11. Fig.12., Fig.13. and Fig.14.shows the implementation circuit, hardware connection and temperature and fan status display of the Temperature Monitoring System.

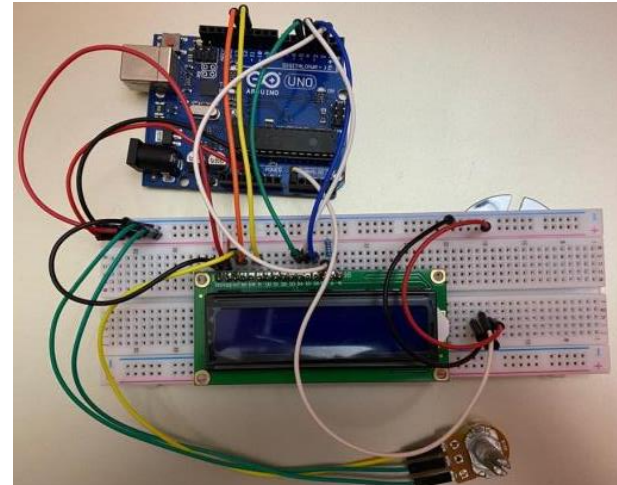

Fig.11. Temperature Monitoring System- Implementation circuit

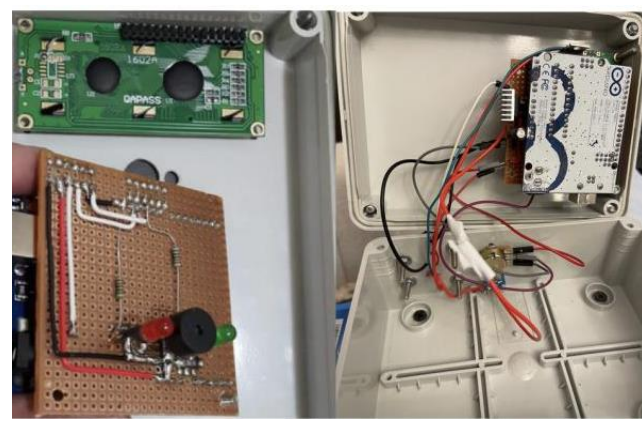

Fig.12. Temperature Monitoring System - Hardware Connection

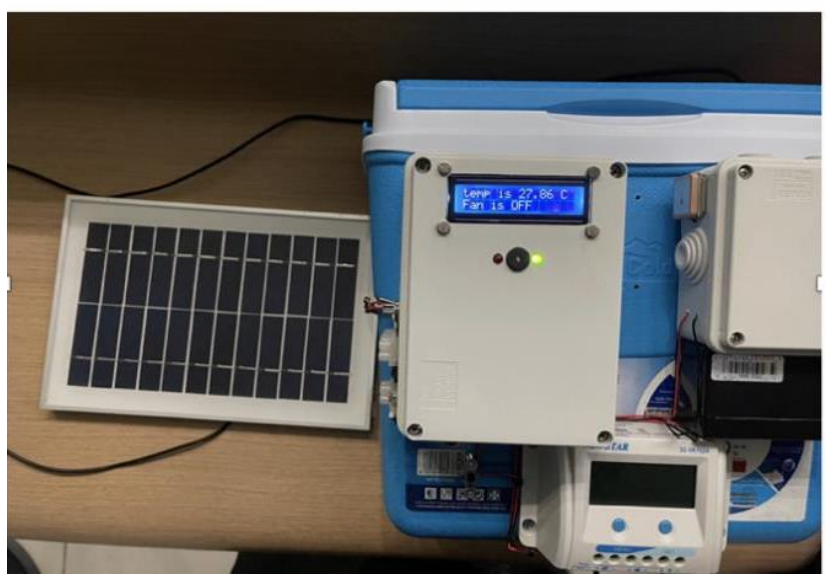

Fig.13. Temperature Monitoring System

Fig 15 shows the Vaccine Temperature Monitoring and Tracking Box. 


\section{International Journal of Engineering Applied Sciences and Technology, 2021 \\ Vol. 6, Issue 2, ISSN No. 2455-2143, Pages 5-12 \\ Published Online June 2021 in IJEAST (http://www.ijeast.com)}

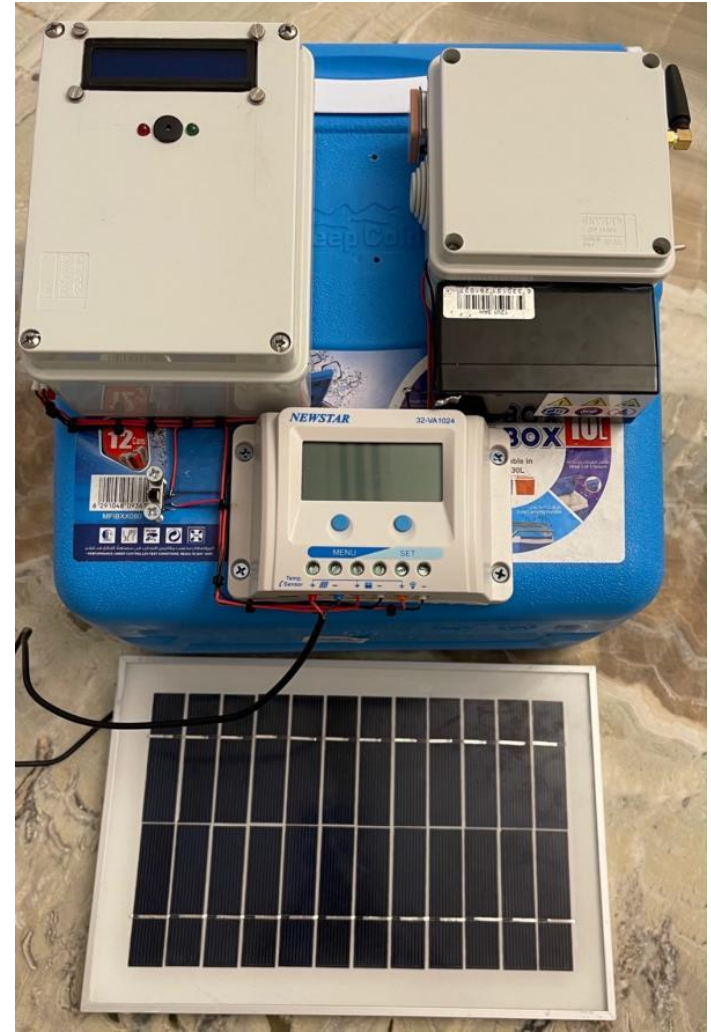

Fig. 15. Temperature Monitoring and Tracking Vaccine Box

The project implemented to track the location and control the temperature inside the box. The whole system was group into three functional blocks, namely, the power supply unit, tracking system and temperature monitoring system.

\section{A. The Power Supply Unit}

The power supply is essential to a circuit for it to function correctly. The system will receive the solar energy from the sun via PV (Solar Panel) and convert the free energy to electrical power. It goes to SCC (Solar Charger Controller) to charge and regulate the battery. If the battery is fully charged, the SCC is responsible for voltage and current regulation or cut off the charging to avoid overcharging the battery. The battery is the storage of electrical energy and supplies the GPS and temperature controller box. The power source gets work from either the battery or the sun's energy when the PV is under the sunlight during the day.

\section{B. Tracking System}

The tracking system prototype worked using three main components such as NEO-6M GPS Module, SIM800L V2.0 GSM/GPRS Module, and Arduino Nano. The whole system is designed to locate at a precise location by turning $\mathrm{ON}$ the unit and waiting until the GSM module connects thru the network and communicates with serial communication via assigned $\mathrm{Rx}$ and Tx port. GPS module will communicate to the serial port and look for a minimum of 3 satellites for an exact location. The 5VDC supplies the circuit via an LM7805 step-down voltage regulator of at least 2-ampere current for the system to work correctly. The external power supply can be 12VDC to 7.5DC; it will be filtered by capacitor before entering the LM7805 voltage regulator. The output will then again filter by a capacitor for a clean DC supply.

GSM modem should have a working micro- size SIM card module with credit to send the recipient's location information. Pin lock for a SIM card module should be disabled as well. When the device is ready, it will send an SMS to a recipient that the unit is ready and activated. The user will send an SMS code 3d.GPSinfo* (at this time based on the code) to the SIM card number inserted on the GSM module. The GSM modem will receive the SMS code and send ATTENTION (AT Command) to Rx pin of Arduino NANO Microcontroller unit (MCU); it will then read the SMS code processed on the MCU. The MCU Tx will ask the GPS thru the Rx port of GPS, GPS module then collect information of NMEA code then send it via GPS Tx thru MCU Rx. The NMEA code will be processed and manipulate by MCU and send the data back to GSM Rx. GSM modem will automatically send the information to the recipient upon processing the AT Command.

\section{Temperature Monitoring System}

The system's primary purpose is to monitor the temperature. Four controlled components, such as motor fan, buzzer, red LED, and green LED, will be noted during the system for a given temperature range. At present, the temperature range was set to 15 Degrees Celsius lower limit temperature and 35 Degrees Celsius upper limit temperature. If the temperature inside the box is greater than or equal to 35, the MCU (Microcontroller Unit) will start the motor fan, the red LED will blink, and the buzzer will warn. If the temperature is within the range, the green LED will flash, the buzzer is muted, and the motor fan is stopped. However, if the temperature falls below or equal to 15 degrees Celsius, the red LED blinks, and the buzzer will give a sound notification.

\section{CONCLUSIONS}

This project is the definitive solution to the vaccine temperature monitoring and tracking system that will be provided at all the stages precisely until it reaches the hospital. The creation of a cold chain will be the only way to preserve the vaccine at the proper temperature. In this project, we developed a reliable vaccine temperature-monitoring device for storing and transporting COVID-19 vaccines. The project gives the user the ability to specify the needed temperature range, and when it starts working, the temperature will display on the LCD screen provided. When the temperature goes out of the range, an alarm will start working, and LED will keep blinking until the temperature gets regulated. This system also 


\section{International Journal of Engineering Applied Sciences and Technology, 2021 \\ Vol. 6, Issue 2, ISSN No. 2455-2143, Pages 5-12 \\ Published Online June 2021 in IJEAST (http://www.ijeast.com)}

contains a GPS and GSM system to track the vaccine box's location.

\section{REFERENCE}

[1] Technology Solutions for Global Health, February2018, "A Practical Resource Guide for Health Workers". Geneva:WHO;2004., https://path.azureedge.net/media/documents/DT_Freeze_ Prev Vacc Carrier Technology Updates_Feb_2018.pdf

[2] Anna Nagurney John F. Smith Memorial Professor of Operations Management. (2020, October 06). (Keeping coronavirus vaccines at subzero temperatures during distribution will be hard, but likely key to ending pandemic, 2020). Retrieved September 30, 2020, from https://theconversation.com/keeping-coronavirusvaccines-at-subzero-temperatures-during-distributionwill-be-hard-but-likely-key-to-ending-pandemic-146071

[3] Corum, J., Wee, S., \& Zimmer, C. (2020, June 10). Coronavirus Vaccine Tracker. Retrieved September 30, 2020,https://www.nytimes.com/interactive/2020/science/c oronavirus-vaccine-tracker.html

[4] Dr Tim Davies, November 2015-2017, Screening and Immunisation Team, Public Health Commissioning, Policy and Procedure for Maintaining the Vaccine Cold Chain,https://www.england.nhs.uk/mids-east/wpcontent/uploads/sites/7/2015/07/cold-chain.pdf

[5] Immunization in practice, Module3: The cold chain , https://vaccine-safety training.org/tl_files/vs/pdf/Module3_IIP.pdf

[6] GPS GSM Tracker. (n.d.). Retrieved October 9, 2020, from https://www.liveviewgps.com/gps gsm tracker.html

[7] (vaccine Storage and Handling Toolkit, 2020)[8] Sea Freeze of America. (n.d.). Retrieved October 1, 2020.U.S.Department of Health and Human Services ,centers for Disease Control and Prevention ,November 2020, Vaccine Storage and Handling Toolkit , https://www.cdc.gov/vaccines/hcp/admin/storage/toolkit/s torage-handling-toolkit.pdf

[8] (MARINE REFRIGERATION, n.d.).Sea Freeze of America. (n.d.). Retrieved October 1, 2020, from http://www.seafreezeinc.com/coldplates.html

[9] (HOW TO USE SOLAR PANELS TO POWER THE ARDUINO, n.d.) .How to Use Solar Panels to Power the Arduino. (2020, June 27). Retrieved October 9, 2020, from https://www.circuitbasics.com/how-to-use-solarpanels-to-power-the-arduino/

[10] (design and analysis of an efficient vaccine cold chain box 2016)

(https://www.researchgate.net/publication/313625762_De sign_and_Analysis_of_an_Efficient_Vaccine_Cold_Chai n_Box
[11] Davoren, J. (2019, January 10). The Difference Between GSM \& GPS. Retrieved October 9, 2020, from https://itstillworks.com/difference-between-gsm-gps$\underline{18430 . h t m l}$

[12] Automatic Temperature Control System Using Arduino, Kyi Kyi Khaing, K. Srujan Raju, G. R. Sinha and Wit Yee Swehttps://www.researchgate.net/publication/339984217 _Automatic_Temperature_Control_System_Using_Ardui $\underline{\text { no }}$

[13] Vaccine Storage and Handling, chapter5, Centers for Disease Control and Prevention (CDC) National Institute of Standards and Technology (NIST). Thermal Analysis of Refrigeration Systems Used for Vaccine Storage, 2009, Household, Dormitory-Style Refrigerators and Data Loggers.

https://www.paho.org/immunization/toolkit/resources/part ner-pubs/ebook/Chapter5-Vaccine-Storage-andHandling.pdf?ua $=1$ 